\title{
Spatial-Temporal Metaphoric Expressions of Time in Mandarin and Cantonese
}

\author{
Zhu Pan
}

\begin{abstract}
While Cantonese speakers share the same cultural background with Mandarin speakers, Cantonese differs sharply from Mandarin in terms of some use of temporal expressions. For example, the concept of "last year" and "next year" in English are expressed as 去年 qunian and 明年 mingnian respectively in oral Mandarin while上年soeng6 nin4 and 下年 haa6 nin4 respectively in oral Cantonese. Aside from the collocation with 年 nian 'year', is there any other difference between Cantonese and Mandarin involving spatial morphemes plus time units? In the present study, we attempt to explore whether there is a difference in space-time metaphors between the two languages and whether the Mandarin speakers and Cantonese speakers have preferences on sagittal axis and vertical axis in terms of spatial-temporal metaphors.
\end{abstract}

Index Terms-Spatial-temporal metaphors, sagittal axis metaphors, vertical axis metaphors, time conceptualization.

\section{INTRODUCTION}

It has been an important question to study spatial-temporal metaphors in the field of linguistics and psychology. Cross-linguistically, are there differences in terms of space conceptualization? Take Mandarin and English as examples; speakers of both languages use horizontal spatial terms to talk about time [1]-[3]. For example, ahead and behind in English can be used to express abstract time as in 'the good times ahead of us' and 'the hardships behind us'. Mandarin speakers also use spatial morphemes, such as 前 qian 'front' and 后 hou 'back', to talk about time, for example, 前天 qiantian 'the day before yesterday', 后天 hounian 'the year after next year'. In addition to horizontal expressions, Mandarin speakers use vertical spatial morphemes, such as 上 shang 'up' and 下 xia 'down', to talk about time [1], [3], [4]. For example, 上周 shang zhou 'last week', 下周 xia zhou 'next week', where the spatial morphemes 上 shang represents the time referent in the past and 下 xia stands for the time referent in the future. It has been reported that English also uses vertical spatial metaphors to express time (e.g., 'the meeting was coming up'), but such usage is extremely rare and note that in English, both down and up refer to the future [1], [3]. In addition to the differences between Chinese and

Manuscript received December 24, 2017; revised February 20, 2018.

Zhu Pan is with the Hong Kong Polytechnic University, Hong Kong (e-mail: xiaopan.zhu@connect.polyu.hk).
English, there exist some intriguing discrepancies of time expressions between Mandarin and other Chinese languages. For instance, the vertical metaphors in Cantonese like 上年 soeng6 nin4 'last year' and 下年haa6 nin4 'next year are not acceptable in spoken Mandarin and but appears in Chinese news writing style [4]. It is this difference that aroused the author's interests. Then, aside from the collocation with 年 nian 'year', is there any difference between Cantonese and Mandarin in common collocation involving spatial morphemes plus time units? However, no study has systematically investigated such linguistic differences.

To fill in this research gap, it is necessary to investigate whether there is a difference between different Chinese languages in terms of space-time metaphoric expressions and how speakers of different Chinese languages apply space-time metaphors. Since Mandarin is the official language in China and Cantonese is very influential in Hong Kong. I propose to study the spatial-temporal perception of Mandarin and Cantonese speakers in Hong Kong. The focus will be on the spatial-temporal metaphoric expressions and time conceptualization in the two languages contexts

\section{The COMPARISON OF TIME EXPRESSIONS BETWEEN TWO GROUP}

As has been mentioned before, the author attempts to explore whether there is a difference of time conceptualization between the speakers in Mandarin and in Cantonese. According to previous empirical studies, I found that different experimental materials can likely yield the divergence in representation preponderance of spatial axes. For instance, some select 月 yue 'month' [5]; some choose 星期 xingqi 'week', 月 yue 'month', 季度 jidu 'quarter' [6]; and some opt for 天 tian 'day' [7]. Nonetheless, in Chinese languages, concepts of month and week are often expressed by vertical metaphors such as 上 shang 'up' and 下 xia 'down', whereas the concept of day is more commonly used with 前 qian 'front' and 后 hou 'back' spatial metaphor for representation. To avoid system-internal bias introduced by stimuli, I include temporal compounds containing spatial and time morphemes. The spatial morphemes refer to horizontal spatial metaphors (前 qian 'front' and 后 hou 'back') and vertical spatial metaphors ( 上 shang 'up' and 下 xia 'down'); time morphemes refer to those time units such as 世纪 shiji 'centrury', 年nian 'year', 季度jidu 'quarter', 月yue 'month', 星期xingqi ‘week’, 周zhou 'week’, 天 tian ‘day', 日 ri 'day’, 
小时xiaoshi 'hour', 分钟fenzhong 'minute', 秒miao 'second' (see details of the questionnaire in Appendix 2), hoping to investigate into relatively comprehensive language forms of time expressions.

The participants were instructed to tick the temporal expressions that are acceptable in their opinions and that they could choose more than one answer. 90 Mandarin and 50 Cantonese questionnaires were collected (including language background investigation, see Appendix 1), among which 21 and 18 of them respectively were invalid responses on the grounds that: 1) All/parts of the questions were left unanswered; and/or 2) The same response was given to all different questions, which implied that the respondent was randomly answering through the survey merely for the incentive. In total, 69 Mandarin questionnaires and 32 Cantonese questionnaires are used in the analysis presented below.

Among the 66 sets of examined items, the acceptability of the 11 sets (个年 ge nian/一个年 yi ge nian 'one year', 半个 年 ban ge nian 'half year', 个天 ge tian/个日 ge ri /一个天 $y i$ ge tian / 一个日 yi ge ri 'one day', 半个天 ban ge tian / 半个 日 ban ge ri 'half day', 个分钟 ge fen zhong 'a minute', 个秒 ge miao 'a sceond') was very low and almost every participant believed that these expressions could not be accepted. Therefore, these 11 sets were excluded and the remaining 55 sets were analyzed. We first calculated the number of participants who selected sagittal metaphors and vertical metaphors in each group, and then we calculated the proportion of those who selected the two axes in each group. The results showed that there are both similarities and differences between the two groups.

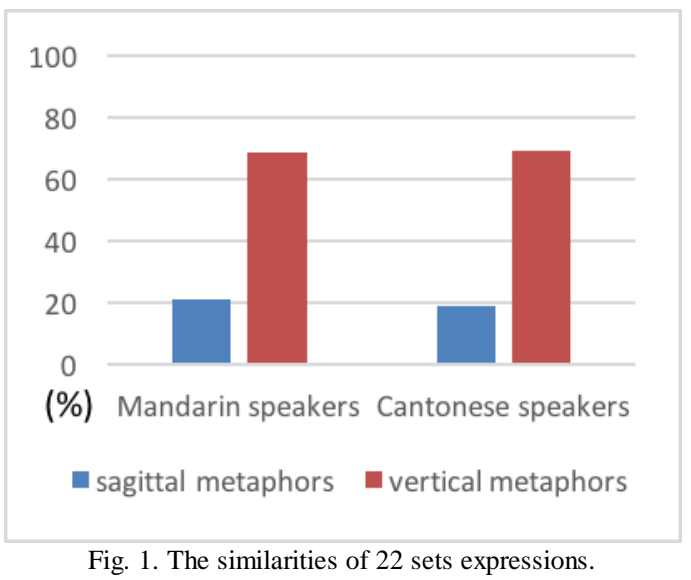

\section{Similarities:}

The participants in both groups used the vertical metaphors more frequently than sagittal metaphors for 22 sets of temporal expressions (such as 世纪shi ji / 个世纪ge shi ji / 一世纪yi shi ji /一个世纪yi ge shi ji 'a century', 半个世纪 ban ge shi ji 'half century', 季度 $j i d u$ / 个季度 $g e j i d u$ /一季度 $y i j i d u$ /一 个季度yi ge ji du 'a quarte', etc.), as shown in Fig. 1. The $y$-axis indicates the proportion of participants' judgement of spatial-temporal metaphors. Both groups have shown distinctly higher percentage of collocation with "vertical metaphors" (68.82\% and 69.34\% in Mandarin and Cantonese group respectively). However, the average proportion of sagittal terms were much lower than vertical terms (only $21.31 \%$ and $19.19 \%$ respectively).

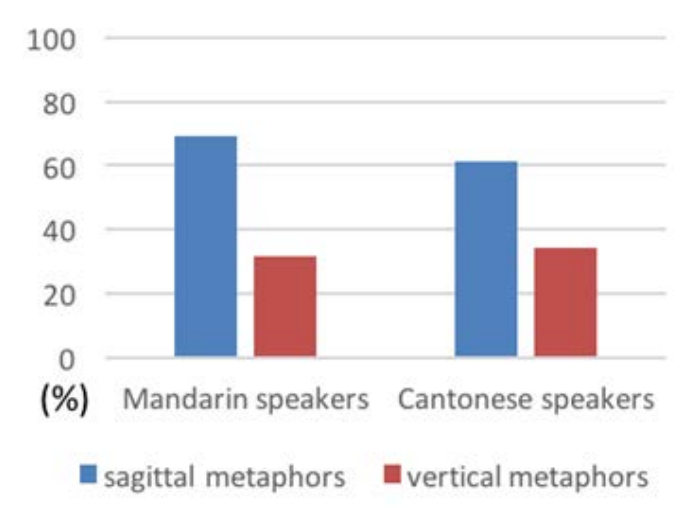

Fig. 2. The similarities of 14 sets expressions.

As shown in Fig. 2, the $y$-axis indicates the proportion of participants' judgement of spatial-temporal metaphors. Both groups have shown the preference on the higher proportion of collocation with “前qian 'front' and 后hou 'back'” (69.32\% and $61.28 \%$ respectively). The average proportion of vertical terms were lower than sagittal terms (31.45\% and 34.01\% respectively), while judging 14 sets of temporal expressions (for example, 半月ban yue / 半个月ban ge yue 'half month', 半星期ban xing qi / 半个星期ban ge xing qi / 半个周ban ge zhou 'half a week', 天 tian / 一天 yi tian / 日 ri / 一日 yi ri 'one day', 半天 ban tian / 半日 ban ri 'half day', 半小时ban xiao shi / 半个小时ban ge xiao shi 'half an hour' and 半分钟 ban fen zhong 'half a minute').

If time units are ordered into a rank based on the length that each time unit expresses, we found that those 22 temporal expressions that prefer vertical metaphor are longer time units, ranging from世纪 'century’ to 星期 "week", whereas those 14 expressions that prefer sagittal metaphor are shorter temporal concept ranging from月 'month’ to 分钟 ‘minute’ (see Fig. 3).

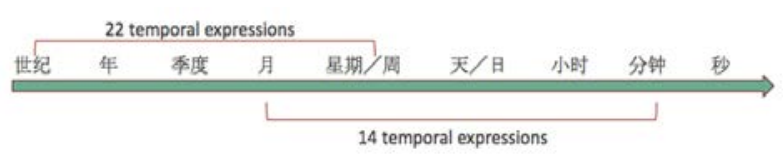

Fig. 3. The distribution of two similarities of two groups.

The result showed that large time units tend to collocate with vertical terms when they express "one" time unit, while the small units tend to collocate with sagittal terms when they express "half" time unit. That is, among the 22 temporal expressions, except for半个世纪 "half century", the other 21 units tend to be expressed with "one" through vertical metaphor, such as 一个世纪 'one century' or 一个月 'one month'. Among the 14 temporal expressions, except for天/日 'day', the other 10 units are more often expressed with "half" with sagittal metaphor, such as 半个月 'half a month', 半周 
'half a week', 半分钟 'half a minute'. One remaining question is what the collocation mechanisms of these temporal expressions is? This is one of the questions the proposed study attempts to answer.

Differences:

There are three differences between Mandarin group and Cantonese group.

First, as shown in Fig. 4, the $y$-axis indicates the proportion of participants' judgement of spatial-temporal metaphors. The proportion of those who selected space-time metaphors on sagittal axis and vertical axis in the Cantonese group was similar (46.95\% and 47.95\% respectively), but the Mandarin group has shown clear preference on sagittal metaphors (66.92\%) than vertical terms (29.8\%), and the collocation with 前qian 'front' and 后hou 'back' was rated higher among the 9 sets of collocation: 半世纪ban shi ji 'half century', 年nian 'year', 半季度ban ji du 'half a quarter', 半周ban zhou 'half week', 一小时yi xiao shi 'one hour', 一分钟yi fen zhong 'one minute', 半个分钟ban ge fen zhong* 'half minute', 一个分钟 yi ge fen zhong* ‘a minute' and 半秒ban miao 'half a second'.

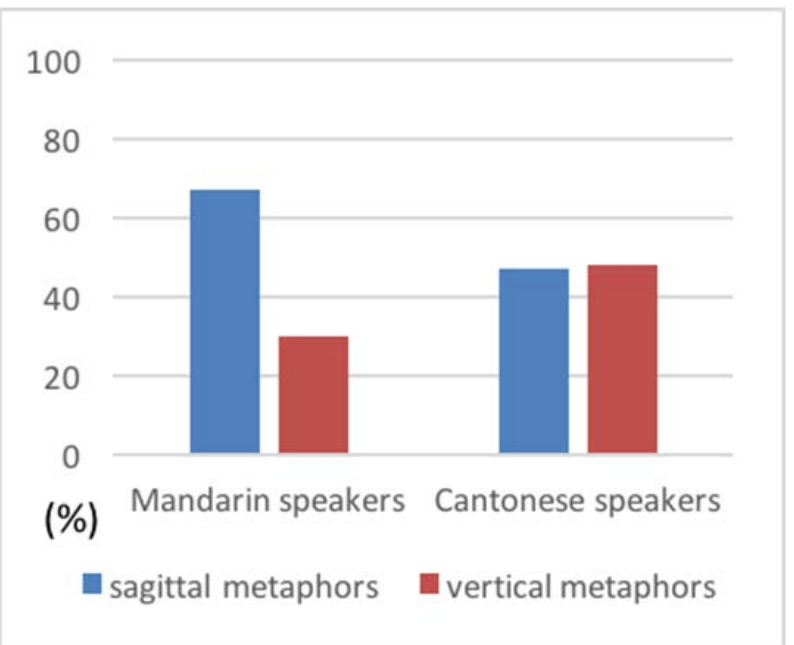

Fig. 4. The first difference of two groups.

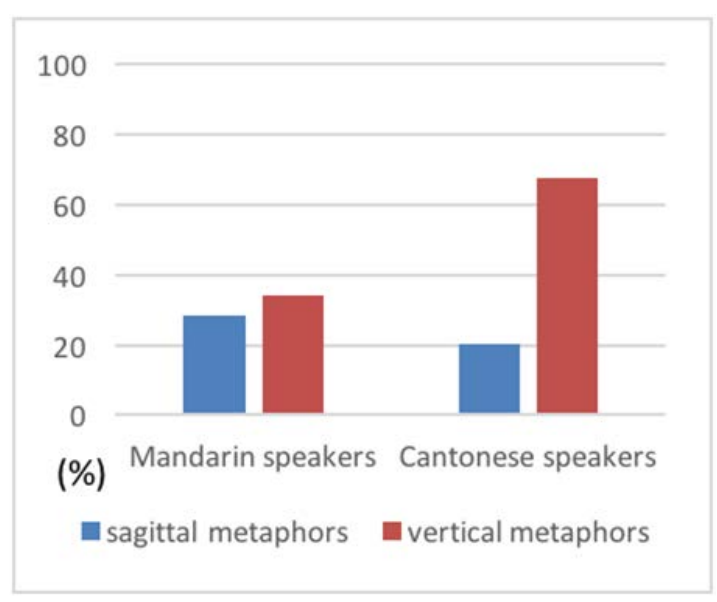

Fig. 5. The second difference of two groups.

Second, as Fig. 5 shows, the $y$-axis indicates the proportion of participants' judgement of spatial-temporal metaphors. In the 5 sets of collocation: 半年ban nian 'half year', 一个月yi ge yue 'one month', 小时xiao shi* 'hour', 分钟fen zhong* 'minute' and 秒miao* 'second', the results of those who selected space-time metaphors on sagittal axis and vertical axis in Mandarin group were similar (difference $\leq 10 \%$, 28.59\% and 34.24\% respectively), but Cantonese group has shown clear preference on vertical metaphors (67.4\%) rather than sagittal metaphorical terms (20.31\%), and they were more apt to elect the collocation with “上 ‘up' and 下 ‘down””.

Third, as Fig. 6 shows, the $y$-axis indicates the proportion of participants' judgement of spatial-temporal metaphors. In the 5 sets of collocation: 半个季度ban ge ji du 'half a quarter', 个小时yi ge xiao shi 'one hour', 一秒yi miao 'one second', 半个秒ban ge miao* 'half a second' and 一个秒yi ge miao* 'one second', the two groups show the opposite tendency. The proportion of those who selected sagittal metaphors (51.15\%) was higher than vertical metaphors (31.86\%) in Mandarin group, but Cantonese group has shown clear preference on vertical metaphors (50.67\%) rather than sagittal metaphorical terms (36.35\%).

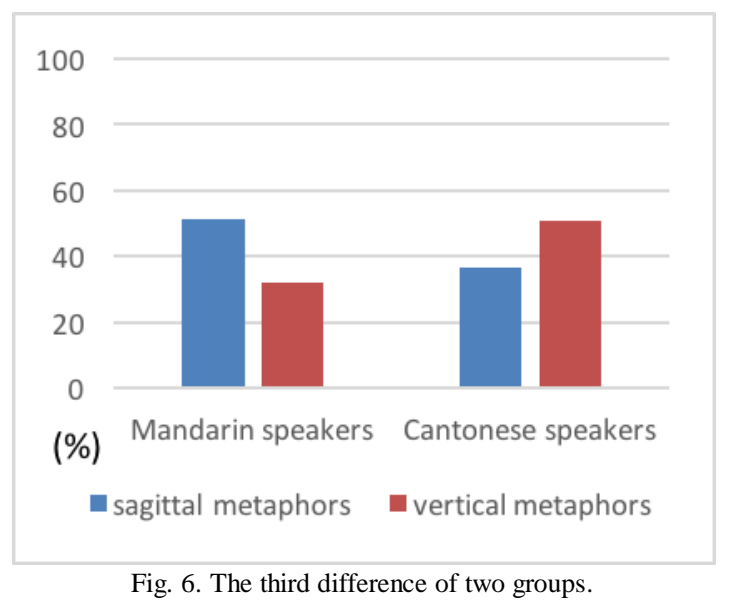

The average percentages of the three differences showed that those who selected sagittal axis and of vertical axis in Cantonese group were $34.53 \%$ and $55.34 \%$ respectively, however, Mandarin group showed an opposite pattern that those who selected sagittal axis and of vertical axis in Mandarin group were $48.89 \%$ and $31.96 \%$ respectively (See Fig. 7).

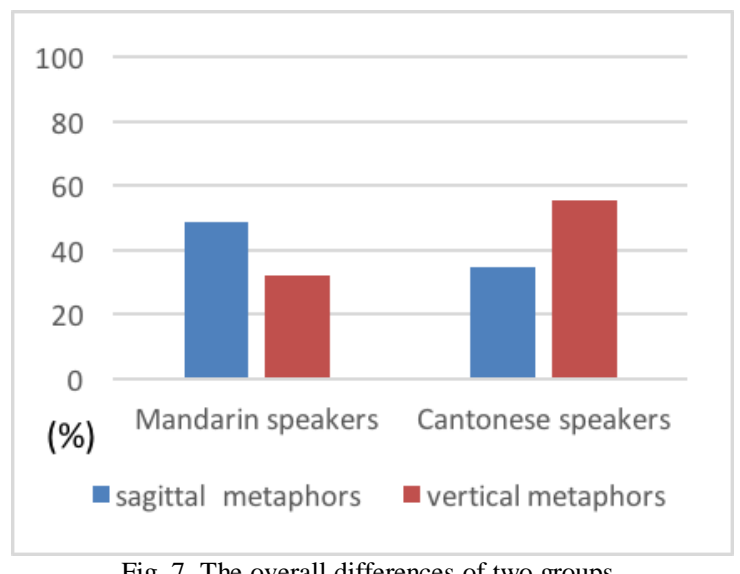

Fig. 7. The overall differences of two groups. 
According to the result, I believe that the Mandarin speakers more frequently use the space-time metaphors on sagittal axis but the Cantonese speakers more frequently used the space-time metaphors on vertical axis. That is to say, the two groups have showed different preference in terms of space-time metaphors.

\section{CONCLUSION}

Cantonese has been viewed as one indepent language as it differs sharply from Mandarin either in voice or vocabulary. As for the spatial-temporal metaphoric expressions, based on the statistical result of the questionnaire survey, it can be seen that the Cantonese speakers are more inclined to use vertical terms to express time while Mandarin speakers rely on sagittal axis more. In reality, a lot of previous studies have noticed the putative discrepancies between Mandarin and other Western languages, especially English [6], [8]-[13], but to the best of my knowledge, the cross-linguistic variation between Mandarin and other Chinese languages have received little focus. In present study, we compared the time expressions cross-linguistically from a new perspective, to some extent adding to the broader body of work on cross-linguistic differences in cognition. The current study may partially reveal that there are some interesting discrepancies of time expressions between Mandarin and Cantonese. However, the issue regarding whether such differences in metaphoric use in language cause different ways in which people construct time still requires further examinations and clarifications.

\section{APPENDIX 1 LANGUAGE BACKGROUND QUESTIONNAIRE}

\section{Part I:}

1. Name: 2. E-mail: 3. Phone: 4. Age: 5.Gender: Male/Female

6. Education background: Undergraduate/Postgraduate 7. Birthplace: 8. Current residence:

9. How long have you been living in current residence?__(years)/(months)

10. Which country/countries (region/regions) did you live in before the age of seven?

\section{Part II:}

1. How many languages (including dialect) do you speak?

\begin{tabular}{|l|l|l|l|l|l|l|l|}
\hline & $\begin{array}{l}\text { Language } \\
\text { (including } \\
\text { dialects) }\end{array}$ & $\begin{array}{l}\text { At what age } \\
\text { did you start } \\
\text { studying? }\end{array}$ & $\begin{array}{l}\text { In which country } \\
\text { (region) did you } \\
\text { study? }\end{array}$ & $\begin{array}{l}\text { Place of } \\
\text { studying } \\
\text { (home, } \\
\text { school, cram } \\
\text { school) }\end{array}$ & $\begin{array}{l}\text { Whom did you } \\
\text { learn from } \\
\text { (teacher, } \\
\text { parents, } \\
\text { self-study)? }\end{array}$ & $\begin{array}{l}\text { How long have } \\
\text { you lived in the } \\
\text { region where the } \\
\text { language is the } \\
\text { official language? }\end{array}$ & $\begin{array}{l}\text { Fluency } \\
\text { little; } \\
\text { fluent) }\end{array}$ \\
\hline $\begin{array}{l}\text { Native } \\
\text { language }\end{array}$ & & & & & & 1234567 \\
\hline $\begin{array}{l}\text { Second } \\
\text { language }\end{array}$ & & & & & & & 123456 \\
\hline Third language & & & & & & & \\
\hline Fourth language & & & & & & & 1234567 \\
\hline
\end{tabular}

2. Which language (including dialect) do you most frequently use when speaking with your parents?

Speaking with your mother: Cantonese/Mandarin/dialect/English/Other (please indicate: )

Speaking with your father: Cantonese/Mandarin/dialect/English/Other (please indicate: )

3. Which language (including dialect) do your parents speak at home?

Father: Cantonese/Mandarin/dialect/English/Other (please indicate: )

Mother: Cantonese/Mandarin/dialect/English/Other (please indicate:

4. Do you often read the publication with vertical layout? ( $1=$ nearly zero; $7=$ often read $)$

\begin{tabular}{|c|c|c|c|c|c|c|}
\hline Books: & 2 & 3 & 4 & 5 & 6 & 7 \\
\hline Magazine: 1 & 2 & 3 & 4 & 5 & 6 & 7 \\
\hline Newspaper: 1 & 2 & 3 & 4 & 5 & 6 & 7 \\
\hline
\end{tabular}

5. Which language (including dialect) do you most frequently use when speaking with others?

Cantonese/Mandarin/dialect/English/Other (please indicate:

6. Which language do your most frequently read? 


\section{Chinese/English/Other (please indicate:}

\section{Part III}

1. Do you have dyslexia? No/Yes

2. Are you left-handed or right-handed?

3. Are any of your family members left-handed? No/Yes (If Yes, who? )

4. Eyesight: Normal/Normal after correction/I cannot see clearly.

5. Hearing: Normal/Normal after correction/I cannot hear clearly.

Appendix 2

The following are the time expressions composed of spatial terms "front, back, up and down" and the time units. Please choose ( the time collocations that are acceptable in oral Mandarin (Cantonese), you can choose more than one.

\begin{tabular}{|c|c|c|l|l|l|l|}
\hline Shiji ‘century' & ( ) shiji & ( ) ge shiji & ( ) ban shiji & ( ) yi shiji & ( )ban ge shiji & ( ) yi ge shiji \\
\hline Qian ‘front' & & & & & & \\
\hline Hou ‘back' & & & & & & \\
\hline Shang ‘up' & & & & & & \\
\hline Xia ‘down' & & & & & & \\
\hline
\end{tabular}

\begin{tabular}{|c|l|l|l|l|l|l|}
\hline Nian 'year' & ( ) nian & ( ) ge nian & ( ) ban nian & ( ) yi nian & ( )ban ge nian & ( ) yi ge nian \\
\hline Qian 'front' & & & & & & \\
\hline Hou 'back' & & & & & & \\
\hline Shang ‘up' & & & & & & \\
\hline Xia ‘down' & & & & & & \\
\hline
\end{tabular}

\begin{tabular}{|c|c|c|c|c|c|c|}
\hline Jidu 'quarte' & ( ) jidu & ( ) ge jidu & ( ) ban jidu & ( ) yi jidu & ( )ban ge jidu & ( ) yi ge jidu \\
\hline \multicolumn{7}{|l|}{ Qian 'front' } \\
\hline \multicolumn{7}{|l|}{ Hou 'back' } \\
\hline \multicolumn{7}{|l|}{ Shang 'up’ } \\
\hline \multicolumn{7}{|l|}{ Xia ‘down’ } \\
\hline Yue 'month' & ( ) yue & ( ) ge yue & ( ) ban yue & ( ) yi yue & ()ban ge yue & () yi ge yue \\
\hline \multicolumn{7}{|l|}{ Qian 'front' } \\
\hline \multicolumn{7}{|l|}{ Hou 'back' } \\
\hline Shang 'up' & & & & & & \\
\hline Xia ‘down’ & & & & & & \\
\hline
\end{tabular}

\begin{tabular}{|c|c|c|c|c|c|c|}
\hline Xingqi 'week' & ( ) xingqi & ( ) ge xingqi & ( ) ban xingqi & ( ) yi xingqi & ()bange xingqi & ( )yi ge xingqi \\
\hline Qian 'front' & & & & & & \\
\hline Hou 'back' & & & & & & \\
\hline Shang ‘up’ & & & & & & \\
\hline Xia 'down' & & & & & & \\
\hline
\end{tabular}

\begin{tabular}{|c|l|l|l|l|l|l|}
\hline Zhou 'week' & ( ) zhou & ( ) ge zhou & ( ) ban zhou & ( ) yi zhou & ( )ban ge zhou & ( ) yi ge zhou \\
\hline Qian 'front' & & & & & & \\
\hline Hou 'back' & & & & & & \\
\hline Shang 'up' & & & & & & \\
\hline Xia 'down' & & & & & & \\
\hline
\end{tabular}

\begin{tabular}{|c|c|c|c|c|c|c|}
\hline Tian 'day' & ( ) tian & ( ) ge tian & ( ) ban tian & ( ) yi tian & ( )ban ge tian & ( ) yi ge tian \\
\hline Qian 'front' & & & & & & \\
\hline Hou 'back' & & & & & & \\
\hline Shang 'up' & & & & & & \\
\hline Xia 'down' & & & & & & \\
\hline
\end{tabular}

\begin{tabular}{|c|c|c|c|c|c|c|}
\hline Ri ‘day’ & ( ) ri & ( ) ge ri & ( ) ban ri & ( ) yi ri & ( )ban ge ri & ( ) yi ge ri \\
\hline \multicolumn{7}{|l|}{ Qian 'front' } \\
\hline \multicolumn{7}{|l|}{ Hou 'back' } \\
\hline \multicolumn{7}{|l|}{ Shang 'up' } \\
\hline \multicolumn{7}{|l|}{ Xia ‘down' } \\
\hline Xiaoshi 'hour' & ( ) xiaoshi & ( ) ge xiaoshi & ( ) ban xiaoshi & ( ) yi xiaoshi & ()bange xiaoshi & ()yi ge xiaoshi \\
\hline \multicolumn{7}{|l|}{ Qian 'front' } \\
\hline \multicolumn{7}{|l|}{ Hou 'back' } \\
\hline \multicolumn{7}{|l|}{ Shang 'up' } \\
\hline Xia ‘down’ & & & & & & \\
\hline
\end{tabular}




\begin{tabular}{|c|l|l|l|l|l|l|}
\hline Fenzhong 'minute' & ( ) fenzhong & ( ) ge fenzhong & ( ) ban fenzhong & ( ) yi fenzhong & ( )ban ge fenzhong & ( )yi ge fenzhong \\
\hline Qian 'front' & & & & & & \\
\hline Hou 'back' & & & & & & \\
\hline Shang 'up' & & & & & & \\
\hline Xia 'down' & & & & & & \\
\hline
\end{tabular}

\begin{tabular}{|c|l|l|l|l|l|l|}
\hline Miao ‘second' & ( ) miao & ( ) ge miao & ( ) ban miao & ( ) yi miao & ( )ban ge miao & ( ) yi ge miao \\
\hline Qian 'front' & & & & & & \\
\hline Hou ‘back’ & & & & & & \\
\hline Shang ‘up' & & & & & & \\
\hline Xia ‘down’ & & & & & & \\
\hline
\end{tabular}

\section{REFERENCES}

[1] A. Scott, "The vertical dimension and time in Mandarin," Australian Journal of Linguistics, vol. 9, pp. 295-314, 1989.

[2] J. H. Y. Tai, "Translation by Ye Feisheng, meager opinion on Chinese functional grammar based on cognition (2nd half)," Linguistics Abroad, vol. 1, pp. 25-33., 1991.

[3] C. Lan, "A cognitive approach to spatial metaphors in English and Chinese," Doctoral thesis, Hong Kong Polytechnic Univ., 1999.

[4] D. Yu, "Vertical time expressions in ancient Chinese," Language Sciences, vol. 1, pp. 1-10, 2016.

[5] N. Wu, N. Xu, and Y. Zhang, "The facilitation of spatial schema processing on directional temporal expression comprehension," Psychological Science, vol. 4, pp. 853-856, 2007.

[6] J. Y. Chen, "Do Chinese and English speakers think about time differently? Failure of replicating Boroditsky," Cognition, vol. 104, no. 2 pp. 427-436, 2007.

[7] C. Han, Mandarin Speakers' Preferences in Their Spatial Representation of Time, Beijing: Beijing Foreign Studies University, 2014.

[8] L. Boroditsky, "Does language shape thought? English and Mandarin speakers' conceptions of time," Cognitive Psychology, vol. 43, no. 1, pp. 1-22, 2001.
[9] T. T. Chan, B. Bergen, M. Hall, and E. Hall, "Writing direction influences spatial cognition," in Proc. the 27th Annual Conference of the Cognitive Science Society, Mahwah, NJ, USA: Lawrence Erlbaum, 2005, pp. $412-417$

[10] O. Fuhrman, K. McCormick, E. Chen, H. Jiang, D. Shu, S. Mao, and L. Boroditsky, "How linguistic and cultural forces shape conceptions of time: English and Mandarin time in 3D," Cognitive Science, vol. 35, pp. 1305-1328, 2011.

[11] V. T. Lai and L. Boroditsky, "The immediate and chronic influence of spatio-temporal metaphors on the mental representations of time in English, Mandarin, and Mandarin-English speakers,” Frontiers in Psychology, vol. 4, pp. 142-151, 2013.

[12] L. Liu and J. Zhang, "A study about the psychological mechanism of space-time metaphor," Exploration of Psychology, vol. 3, pp. 32-36, 2009.

[13] C. S. Tse and J. Altarriba, "Evidence against linguistic relativity in Chinese and English: A case study of spatial and temporal metaphors," Journal of Cognition and Culture, vol. 8, pp. 335-357, 2008.

Zhu Pan is a doctor candidate at Hong Kong Polytechnic University, her main research interests are cognitive linguistics, second language acquisition, teaching Chinese as a foreign language. 